\title{
A Rare case report of Vaginoplasty using amnion graft:
}

\author{
Dr.Deepali Mehra ${ }^{1}$, Dr.Parul Sinha ${ }^{2}$, Dr. Kanika Manchanda ${ }^{3}$, \\ Dr. SaloniMehra ${ }^{4}$, Dr. Bharat Veer Manchanda ${ }^{5}$ \\ ${ }^{I}$ Post Graduate In Dept Of Obstetrics \& Gynaecology, Era's Lucknow Medical College, Lucknow \\ ${ }^{2}$ Asso. Prof in Dept of Obstetrics \& Gynaecology, Era's Lucknow Medical College, Lucknow \\ ${ }^{3}$ Post Graduate In Dept Of Obstetrics \&Gynaecology, C..M.C, Ludhiana \\ ${ }^{4}$ Post Graduate In Dept Of Surgery, Subharti Medical College, Meerut \\ ${ }^{5}$ Ass. Prof in Dept of Medicine, Subharti Medical College, Meerut
}

\begin{abstract}
Vaginal agenesis is congenital anomaly of female genital tract. It is estimated to occur in 1 in 40005000 live births.In our case an unmarried girl presented to us with amenorrhoea her vaginoplasty was done using amniotic membrane as graft: The postoperative period was uneventful and patient was discharged with advice as how to wear the mould. This technique is simple and safe and provides satisfactory and functional vagina in majority of patients.
\end{abstract}

Keywords: vaginoplasty, vaginal agenesis, graft, amenorrhoea

\section{Introduction}

Vaginal agenesis is congenital anomaly of female genital tract. Such malformations of vagina are common but serious problems. Vaginal agenesis is estimated to occur in 1 in 4000-5000 live birth[1]. Most commonly seen with Mayor-rokitansky -kusterhauser syndrome and Androgen insensitivity syndrome.[2] Vaginal construction or reconstruction has become a well established method to permit or restore sexual function and a variety of procedures have been described.The most popular method involves lining a surgically created space either with partial thickness skin graft or with amnion : other techniques to create a neovagina are the non surgical Frank technique which relies on serial dilation of vaginal pouch. In 1910 Davis was first to report the use of foetal membranes as surgical material in skin implantation, since then use of amniotic membrane in surgery has been expanded .[3] In 1934 Brindeau[4]used human amnion to construct the vagina for a patient with mullerian agenesis.In our study amniotic membrane have been used to line the artificially constructed vagina.

\section{Case Report}

A 15 yr old unmarried girl with primary amenorrhoea and pain in abdomen presented to us in OPD of Era's Lucknow Medical College and hospital. There was no history of Diabetes Mellitus, Hypertension, Tuberculosis or any surgical exposure. On per abdominal examination a mass of about 20 week size felt. On local examination axillary hair present, breast development normal, Tanner stage 5, pubic hair present.

She underwent preoperative investigations which included blood investigations and ultrasound. Drainage of haematocolpos, haematometra was done followed by vaginoplasty .Amniotic membranes was obtained under sterile condition from elective caesarean section. Amnion donors were screened for Hepatitis B \& C, HIV. Inner amnion membrane was separated from outer membrane and rinsed in sterile normal saline solution. The patient was placed in lithotomy position and after catheterization part was painted and draped . A transverse incision was made and a potential space was created in between bladder and urethra and rectum. A vaginal mould was made using a syringe wrapped with foam covered with latex condom and sterilized with cidex solution. The amnion graft was fixed to mould by suturing the edges of amnion to mould. Labia majorawas sutured with loose sutures to hold the mould by suturing the edges of amnion to mould. Patient was givem antibiotic for 7 days. Mould was removed on day9 along with catheter . Vaginal douching was done . Patient was counseled about method of placement, removal and washing of mould to facilitate further change of mould itself. Patient was discharged with advice to wear the mould for 3 month and to visit forthnightly.Overall Post operative period was uneventful and patient had menses on $1^{\text {st }}$ feb2016 


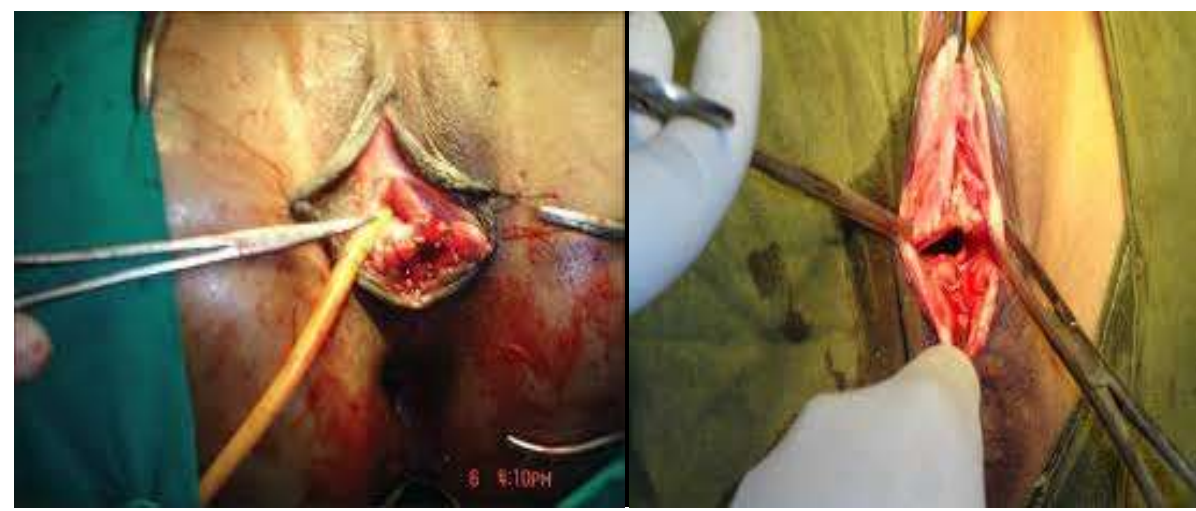

\section{Discussion}

Many techniques have been described for vaginal agenesis though ideal method for vaginoplasty is not currently known and depends on numerous factors including patients condition, surgeon's experience and patient's and surgeon's preference.Vaginoplasty by modified Abbe McIndoe procedure using amnion graft should be recommended in developing countries. It is simple safe and effective and requires less expertise.Faulke et al ${ }^{[5]}$ have demonstrated microscopic evidence of new vessel formation and suggested that an angiogenic factor is produced by amnion. There is no problem with immune rejection because amnion does not express histocompatibility antigens and Akle et $\mathrm{al}^{[}$. The amnion membrane readily available, easily stored and inexpensive can be used without sterilization as a graft for vaginal reconstruction.

\section{References}

[1]. SaxenaAK,Herman MI. Vaginal Atresia .Webpage. Cited June 022009.

[2]. SarafS,SarafP.McIndoevaginoplasty:revisited Internet J GynecolObstetr 2007:6 Online Journal Cited August 18,2008

[3]. Dua HS, Azuara- Blanca A. Amniotic membrane transplantation. Br J Opthalmol 1999;83:748-52

[4]. Brindeau A Creation d 'unvaginartificiel a l'aide des membranes ovulaires d'un oeuf a terme. GynecolObstet(Paris )1934:29:385 